Retrospective Study

\title{
Pulsed Radiofrequency Application on Femoral and Obturator Nerves for Hip Joint Pain: Retrospective Analysis with 12-Month Follow-up Results
}

Andrea Tinnirello, $\mathrm{MD}^{1,2}$, Manuel Todeschini, $\mathrm{MD}^{1,2}$, Deborha Pezzola, MD ${ }^{1}$, and Sandra Barbieri, MD ${ }^{1,2}$

(taly: ${ }^{2}$ Young Against University of rma, Italy

(1)

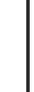

\begin{abstract}
(
carries the potential risk of neuritis and neuroma formation. Pulsed radiofrequency (PRF) is a safer antive to continuous radiofrequency not creating necrosis but a complex neuromodulatory effect on target nerves. There is no published evidence of PRF efficacy after 3 month follow-up.
\end{abstract}

Objectives: This single-center study objective was to evaluate the short and medium term effectiveness of PRF on the femoral articular branches and obturator nerves in patients with chronic hip pain.

Study Design: Retrospective single-center study.

Setting: Italian National Health Service Public Hospital.

Methods: Retrospective analysis of 14 patients treated with PRF for severe hip joint pain (mean numeric rating scale (NRS) $7.7 \pm 1.2$ mean Oxford Hip Score (OHS) $20 \pm 8.4$ ). Mean pain and disability scores were evaluated with NRS and OHS respectively at 1, 3, 6, and 12-month follow-up. All patients were treated with pulsed radiofrequency applied under fluoroscopy on the articular branches of the femoral and obturator nerves for 300 seconds each.

Results: Eight patients out of $14(57 \%)$ reported an NRS reduction $>50 \%$ at 1 month post procedure. Overall, both pain and disability scores were significantly $(P<0.01)$ lower at all follow-up until 6 months, mean NRS at 1, 3, and 6 months was $3.6 \pm 3 ; 4.1 \pm 3.3 ; 4.8 \pm 2.9$ while OHS was $37.6 \pm$ $17.7 ; 35.8 \pm 17.7 ; 35.8 \pm 14$ respectively. At 12 months, NRS was $5.8 \pm 2.4$ while OHS $23.3 \pm 12.7$, it must be pointed out that even if both scores are significantly $(P<0.01)$ lower than basal, only 3 patients out of $14(21 \%)$ maintained a NRS reduction $>50 \%$ from basal at 12 months post procedure. We reported 2 femoral artery punctures without any significant complication.

Limitations: Retrospective study, small sample size.

Conclusions: Pulsed radiofrequency is a safe and effective modality to treat hip joint pain in the short and medium term. Definition of positive outcome predictors is required to reserve radiofrequency treatment only for those patients who can benefit from this procedure.

Key words: Hip joint pain, pulsed radiofrequency, obturator nerve, femoral nerve, interventional pain management, radiofrequency

Pain Physician 2018: 21:407-414 
H ip joint $(\mathrm{HJ})$ pain from osteoarthritis is a common condition with an overall prevalence of $11 \%$ in the general population (1). This condition is often seen in patients with multiple comorbidities. Often, surgery is not an option and conventional drugs have either too many side effects or are ineffective. Conservative management involves both pharmacological and nonpharmacological treatment $(1,2)$. $\mathrm{HJ}$ innervation is provided by articular branches of the femoral, obturator, and sciatic nerves (3). The anterior part of the joint is innervated by branches of the femoral and obturator nerves while branches from the sciatic nerve provide innervation to the posterior part of the joint capsule (3). Obturator and femoral articular branches are easily accessible with the use of relatively constant fluoroscopic markers. Articular branches from the sciatic (via the superior gluteal nerve) are more variable and deeper so they are not routinely used for the neural blockade.

Yavuz et al (4) reported significant pain relief lasting for 3 months after injecting local anesthetic and a steroid near articular branches of the obturator and femoral nerve. These results are similar to those obtained by Flanagan with the intraarticular injection of anesthetic and steroid (5). However, this approach can give only short-term pain relief and repeated intraarticular steroid injections could lead to articular damage (6).

Radiofrequency (RF) application to those target nerves is a possible way to obtain longer pain relief. $\mathrm{RF}$ is a neurolytic technique that uses heat to produce controlled tissue destruction (thermocoagulation). The electrode tip is usually placed near the target nerve. A high frequency continuous electrical current (usually 100 to $1000 \mathrm{kHz}$ ) is then passed through the electrode, which heats up the surrounding tissue creating an area of necrosis (7-13). Tissue temperature must be raised over $50^{\circ} \mathrm{C}$ to enable coagulation necrosis. Lesioning of articular branches of the femoral and obturator nerves with continuous RF has been reported as effective in reducing pain from the $\mathrm{HJ}$ in the short time, up to 6 months (14-16). Continuous RF carries the risk of neuritis and neuroma formation (17), a safer alternative could be pulsed radiofrequency (PRF).

During PRF treatment, electrical current is delivered in short bursts at high voltage, and the generated heat dissipates between these bursts or "pulses" of treatment. In this way, PRF treatment allows for application of the same high-voltage, fluctuating electrical fields as used during conventional RF treatment, but without electrode tip temperature exceeding the temperature of $42^{\circ} \mathrm{C}$, thus prevents damage to the target nerve (18-20). The PRF action mechanism is not completely understood, but it involves structural rearrangement of axonal membrane proteins, modification of gene expression and modulation of inflammatory responses (18-20).

Chye et al (21) compared PRF application on femoral and obturator nerves versus conservative management in 29 patients and reported significantly lower pain and disability scores in the PRF group at every point until the end of their 12 week follow-up period. They also found less medication requirement in the PRF group. However, this study has important selection bias because patients were divided into 2 groups according to consent or refusal to undergo PRF procedure, meaning that patients treated with PRF were more motivated and prone to report better outcome than those treated conservatively.

PRF application for HJ pain has been described only in one more study, a case report of 2 patients who showed a positive outcome 4 months after procedure (22). In our pain management unit, we routinely use PRF for HJ pain in patients resistant to conservative treatment. We report our experience with PRF application on femoral and obturator nerves to assessing the efficacy and durability of this procedure, with followup extended up to 12 months.

\section{Setrting}

Pain management unit of an Italian Public Health Service Hospital.

\section{Methods}

\section{Retrospective Study}

We included 14 consecutive patients with chronic (duration of more than 6 months) HJ pain not responding to conservative treatment. All patients gave written consent to report their data in a study. Institutional Review Board approved our study.

Diagnosis of $\mathrm{HJ}$ pain was made after clinical examination (pain in the hip region worsened by walking, inability to sleep on the affected side, positivity of $\mathrm{HJ}$ stress maneuvers), and radiological evaluation of the joint using the Kellgren-Lawrence $\mathrm{HJ}$ arthritis radiological classification (Table 1) $(23,24)$. Conservative management consisted of paracetamol, nonsteroidal antiinflammatory drugs (NSAIDs) (ibuprofen or etoricoxib), and/or opiates (oxycodone/naloxone or tapentadol) in various dosages. 
Patients whose pain was not controlled by pharmacological therapy were scheduled for an anesthetic test block of the articular branches of femoral and obturator nerves, which was performed under fluoroscopic guidance using the technique described by Locher (25). Ropivacaine $0.5 \% 1 \mathrm{~mL}$ for each nerve was injected through a 22-gauge, $80 \mathrm{~mm}$ long spinal needle. The obturator nerve was blocked placing the tip of the needle below the inferior junction between the ischium and the pubis, which is teardrop shaped in the anteroposterior view (Fig.1 left side). To obtain blockade of the femoral nerve articular branch the needle tip was placed below the inferior anterior iliac spine near the anterolateral margin of the $\mathrm{HJ}$ (Fig.1 right side). Before needle positioning femoral artery was identified by palpation and needle was inserted $2 \mathrm{~cm}$ laterally to the pulsation to minimize the risk of accidental puncturing.

Patients were contacted the day after the test block and if they reported at least $50 \%$ pain relief after the procedure they were scheduled for PRF. A small volume of local anesthetic was used to reduce the possibility of medication spread inside the joint capsule because this would have created a false positive response to injection. One patient did not report significant pain relief after the test block and was not proposed PRF treatment. All patients gave consent to the PRF procedure.

\section{PRF Procedure Description}

Patients were awake or lightly sedated, after sterile draping, skin was numbed using $2 \%$ lidocaine, an 18-gauge, $100 \mathrm{~mm}$ RF needle with $10 \mathrm{~mm}$ active tip was positioned under fluoroscopic guidance using anatomical landmarks as described by Locher (Fig. 1) (25). Needle positioning technique was the same as used for the anesthetic test block. After correct positioning, sensory stimulation at $50 \mathrm{~Hz}$ was performed to elicit paresthesias or pain sensation in the $\mathrm{HJ}$ by the patient at $0.5 \mathrm{~V}$. Two $\mathrm{Hz}$ stimulation was then performed to

Table 1. Kellgren-Lawrence radiological classification for hip joint osteoarthritis

\begin{tabular}{||c|l||}
\hline \hline Grade & \multicolumn{1}{|c||}{ Radiological findings } \\
\hline 0 & no radiographic features of OA are present \\
\hline 1 & $\begin{array}{l}\text { doubtful joint space narrowing (JSN) and possible } \\
\text { osteophytic lipping }\end{array}$ \\
\hline 2 & $\begin{array}{l}\text { definite osteophytes and possible JSN on anteroposterior } \\
\text { weight-beari ng radiograph }\end{array}$ \\
\hline 3 & $\begin{array}{l}\text { multiple osteophytes, definite JSN, sclerosis, possible } \\
\text { bony deformity }\end{array}$ \\
\hline 4 & $\begin{array}{l}\text { large osteophytes, malted JSN, severe sclerosis and } \\
\text { definite bony deformity }\end{array}$ \\
\hline
\end{tabular}

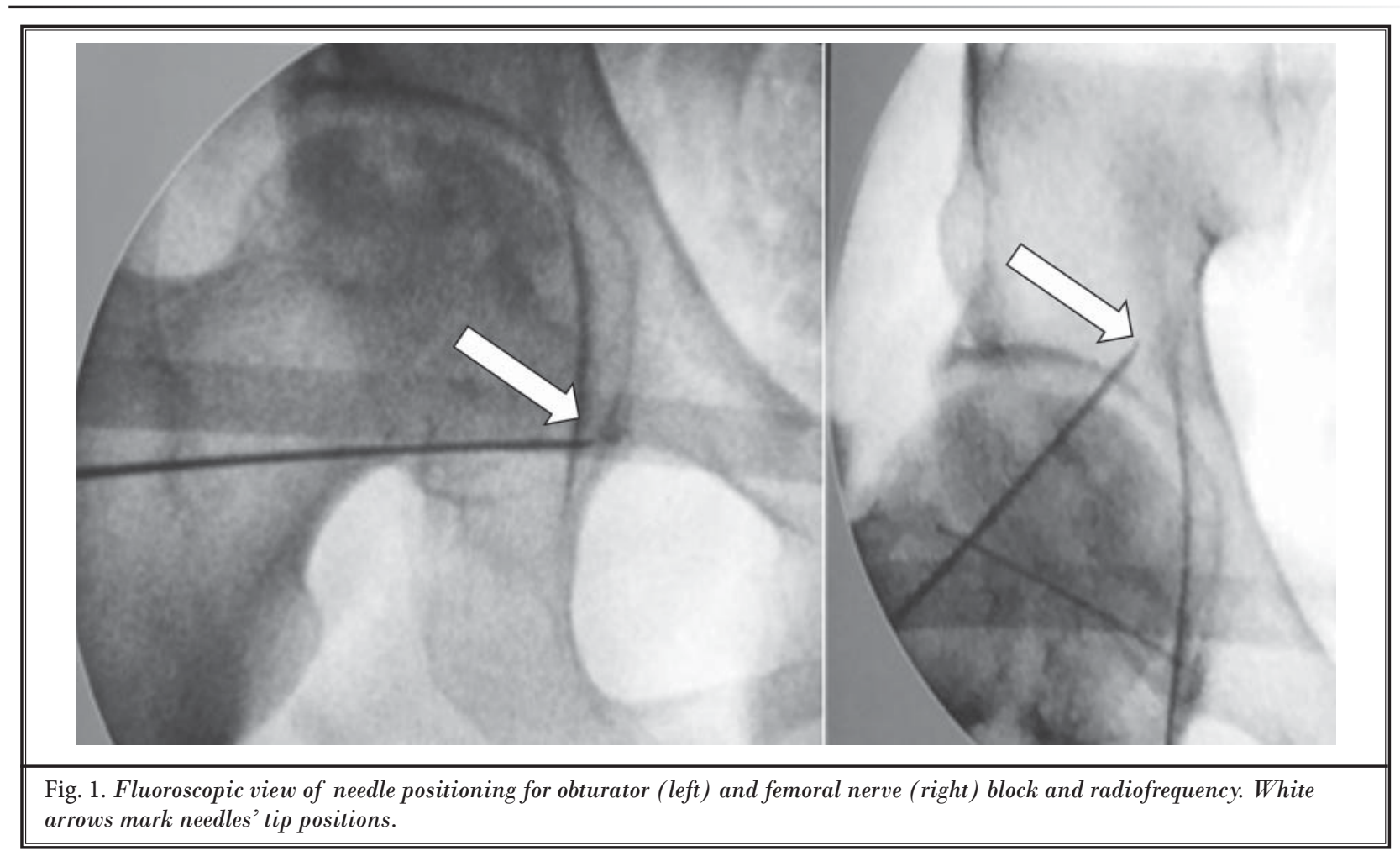


exclude the involvement of motor fibers. PRF was then applied to the target nerves for 300 seconds each, tip temperature was limited to $42^{\circ} \mathrm{C}$. Ropivacaine $0.1 \%$ and methylprednisolone $20 \mathrm{mg}, 2 \mathrm{~mL}$ were injected on the target nerves after the procedure to reduce the risk of neuritis and to alleviate procedure related pain. A compressive bandage to the needle entry zone was applied for 4 hours after the procedure to every patient to reduce the risk of hematoma formation in case of accidental puncturing of a major femoral vessel, patients were monitored for cardiovascular stability, hematoma formation, neurological deficits in the lower limbs and then sent home. Patients were instructed to continue or stop their pain medications as needed.

\section{Study Outcomes}

Patient-reported results for pain and physical function were noted as the primary outcomes of this study. The numerical rating scale (NRS) (NRS; range $=0$ to 10 points; $0=$ "no pain" and $10=$ "worst pain") $(26,27)$ was used to assess pain. The RF procedure was considered a "treatment success" if the patient reported a follow-up NRS score relative to the respective baseline score that was reduced by $\geq 50 \%$ (28). The Oxford Hip Score (OHS) scale (OHS; scale $=0$ to $60 ; 0=$ "severe hip arthritis" and $60=$ "satisfactory joint function") was used to assess the extent of disability associated with hip pain (29). Patients were contacted for follow-up visits with the physician at 1, 3, 6 , and 12 months after the procedure. Procedure-related adverse events such as puncturing of vessels, neuritis, or significant pain after the procedure were recorded.

\section{Statistical Measures}

Means and standard deviations (SD) were calculated for continuous demographic and primary outcome data and, after the normal distribution was assessed by the Kolmogorov-Smirnov test, means were compared by the student t test for with $P \leq 0.01$ indicating signifi-

Table 2. Demographic data of study population.

\begin{tabular}{|l|c|c|c||}
\hline & Mean (SD) & $\max$ & $\min$ \\
\hline Age (years) & $67.11 \pm 13.1$ & 89 & 32 \\
\hline Male (n) & 4 & & \\
\hline Female (n) & 10 & & \\
\hline Body Mass Index (BMI) & $28.6 \pm 6.5$ & 38 & 19 \\
\hline NRS & $7.7 \pm 1.2$ & 10 & 6 \\
\hline OHS & $20 \pm 8.4$ & 32 & 10 \\
\hline Kellgren-Lawrence & 3 & 4 & 2 \\
\hline
\end{tabular}

cant differences. Demographic categorical data (e.g., gender) are expressed as a number of patients in the study group. Kellgren-Lawrence $\mathrm{HJ}$ arthritis radiological classification is reported in Table 1 as a 5-point scale where 0 is no visible radiological signs of arthritis and 4 is severe $\mathrm{HJ}$ arthritis with marked joint space reduction on the radiological examination $(23,24)$. Outcome categorical data (i.e., sub-groups defined by treatment success) are reported as percentages, followed by confidence intervals calculated at the $95 \%$ level.

\section{Results}

All of the 14 patients included reached 12 month follow-up. Demographic data of our population are reported in Table 2. Mean NRS and OHS at different followups are reported in Table 3 and showed graphically in Figs. 2 and 3. The difference in NRS scores from baseline was statistically significant $(P<0.01)$ at every follow-up. At 12 months mean NRS score was $5.8 \pm 2.4$, therefore one year after procedure patients still experienced significantly less pain compared to baseline. Treatment successes (i.e., $\geq 50 \%$ reduction in NRS score at follow-up) (30) were achieved in the majority (9 out of 14 patients representing $64 \%$ of the study population) of patients 1 month after the procedure as shown in Fig. 4.

Regarding functional status, OHS improved significantly after treatment at 1, 3, and 6 months follow-up. At 12 month follow-up, OHS score was still slightly improved from basal, but this difference did not reach statistical significance (OHS at 12 months $23.3 \pm 12.7 P=$ 0.1 ). A study measure of RF denervation durability was the maintenance of a patient's treatment success status (defined as a reduction in NRS of at least $50 \%$ from baseline) from 1 to 12 month follow-up (28). Thus of 9 patients who were treated successfully at 1 month, 5 maintained this status at 6 months, and only 3 were still in this subgroup 12 months after the procedure (Fig. 4). These findings suggest that patients that immediately benefit from the procedure will likely maintain a good pain relief in the medium term, but return near baseline NRS scores after 1 year.

We did not report any significant complication, femoral artery puncture was reported in 2 patients and was treated with a compressive bandage. In these patients, we did not observe hematomas or other significant complications after a puncture. One patient complained of loss of sensation in the medial region of the thigh for 10 hours, the normal perception was resumed after 24 hours without any other neurological deficit. 
PRF Application for Severe Hip Joint Pain

Table 3. Mean NRS and OHS of study population.

\begin{tabular}{|c|c|c|c|c|c|}
\hline & Basal & 1 Month & 3 Months & 6 Months & 12 Months \\
\hline NRS & $7.7 \pm 1.2$ & $3.6 \pm 3$ & $3.9 \pm 3.6$ & $4.5 \pm 3.1$ & $5.8 \pm 2.4$ \\
\hline OHS & $20 \pm 8.4$ & $37.6 \pm 17$ & $35.8 \pm 17.8$ & $33.8 \pm 16.2$ & $27.3 \pm 12.7$ \\
\hline
\end{tabular}

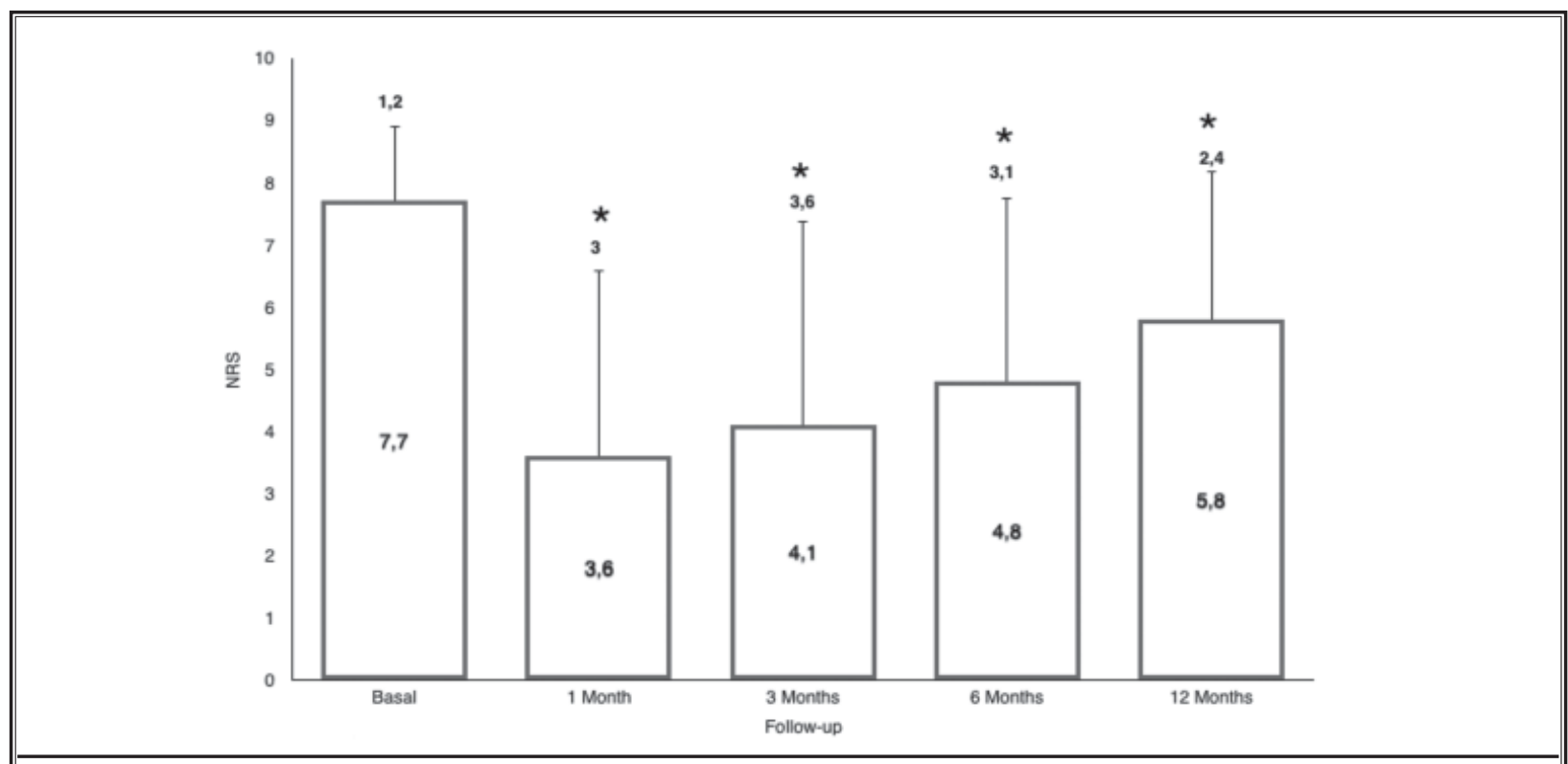

Fig. 2. Mean pain (NRS scores) experienced by the study group over time. Exact mean and standard deviation values are indicated within each bar and adjacent to each whisker, respectively. ${ }^{*}$ Significantly different $(P<0.01)$ mean value compared to that at baseline.

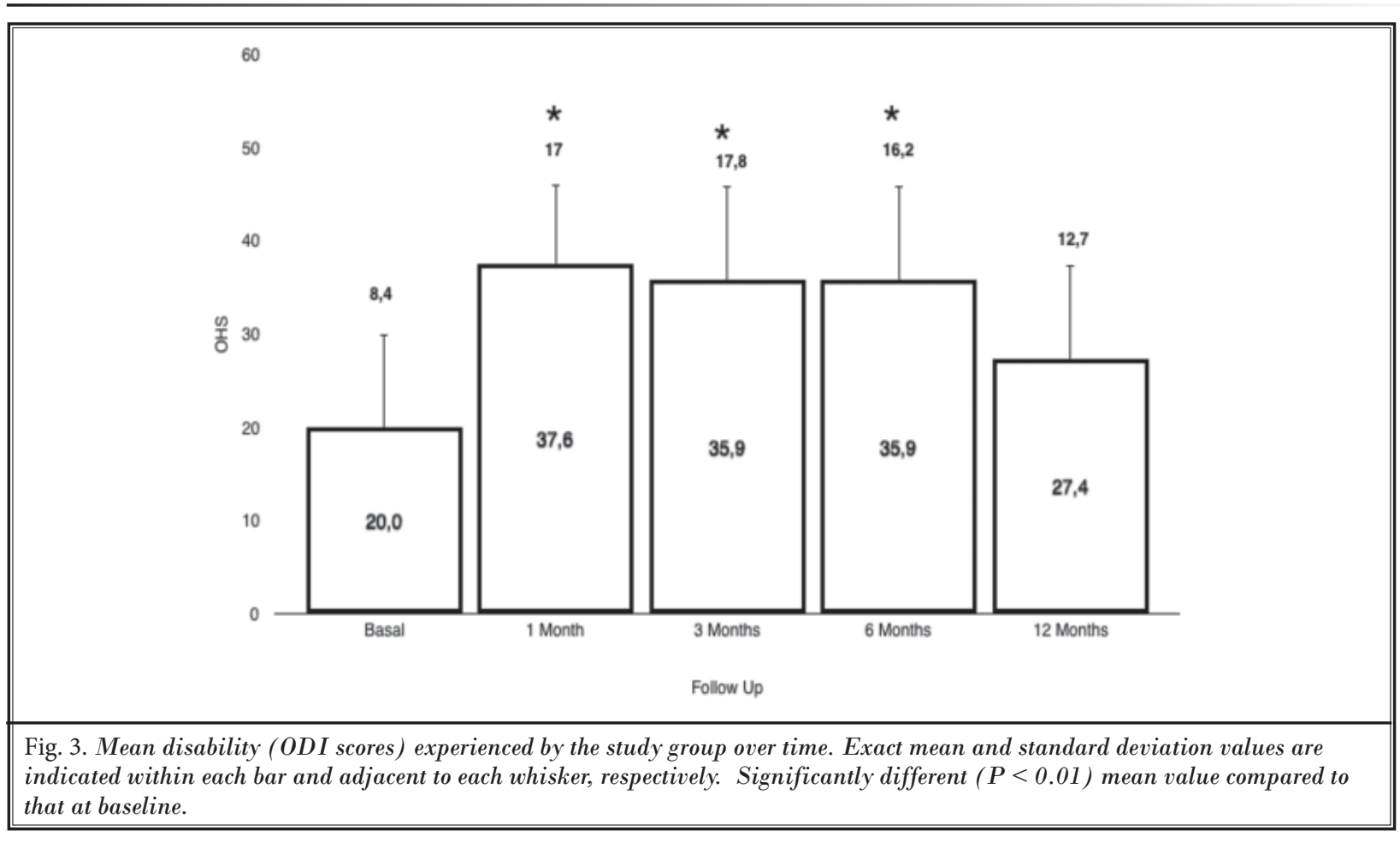

www.painphysicianjournal.com 


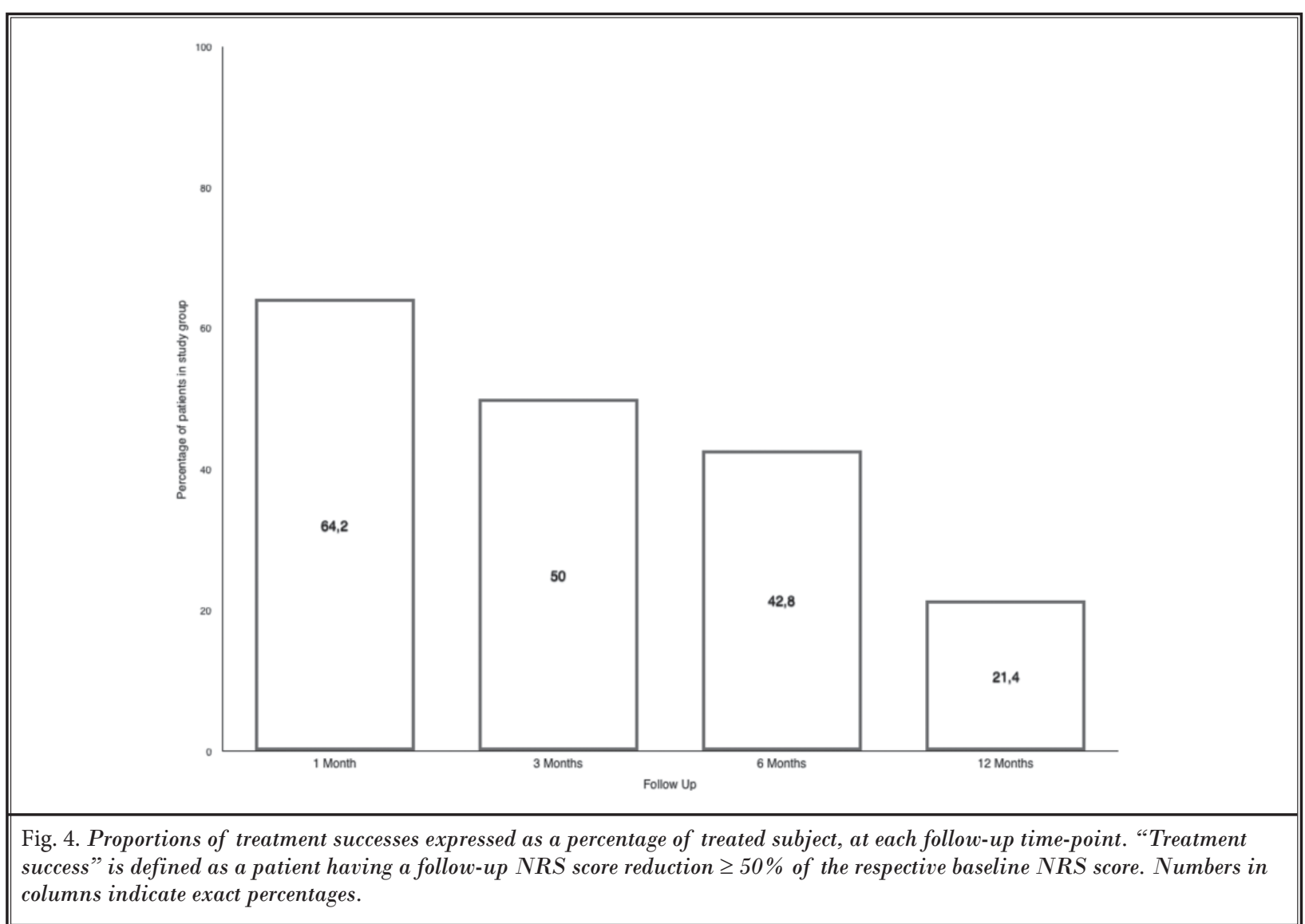

\section{Discussion}

PRF and continuous RF denervation are common procedures to reduce pain arising from peripheral joints or from vertebral structures. Despite its wide application on peripheral joints, there are only a few studies reporting outcomes, the majority of which are case reports or very limited case series.

Application of PRF to the articular nerves is an attractive strategy to reduce pain and disability in patients awaiting joint replacement or who cannot undergo surgery because of the presence of comorbidities, or who are not willing to have surgery.

The first reports of PRF application on the $\mathrm{HJ}$ showed promising results, with patients reporting a significant reduction of pain in the short-term (up to 3 months) when compared to a standard conservative treatment $(21,22)$. Our study is the first reporting outcome at more than 3 month follow-up. Cumulative data suggest a good pain and disability reduction with the application of PRF, mean NRS and OHS were significantly lower than basal at all follow-ups. However, looking only at mean values can be misleading and not representative of the real effect of the procedure.

When mean values of a study group are used to express treatment outcomes, such treatments are significantly effective if all patients consistently benefit to some degree, or if a substantial majority of patients benefit to at least a moderate degree. Therefore, study group means indicating no statistical significance can result from relatively poor responses derived from a majority fraction of the group and can mask highly favorable responses within a minority fraction (30). We addressed these caveats by providing categorical data for pain (NRS) in Fig. 4, and individual data plots of these outcomes for each patient in Fig. 5, to complement the display of pain mean outcome in Fig. 2.

The majority $(64 \%)$ of patients we treated reported a successful outcome and most of them (5 out of 9 patients considered successful 1 month after the procedure) maintained pain relief and disability reduction over time. These results suggest that a key point when proposing PRF treatment is to know which patients could benefit from the procedure. 
PRF Application for Severe Hip Joint Pain

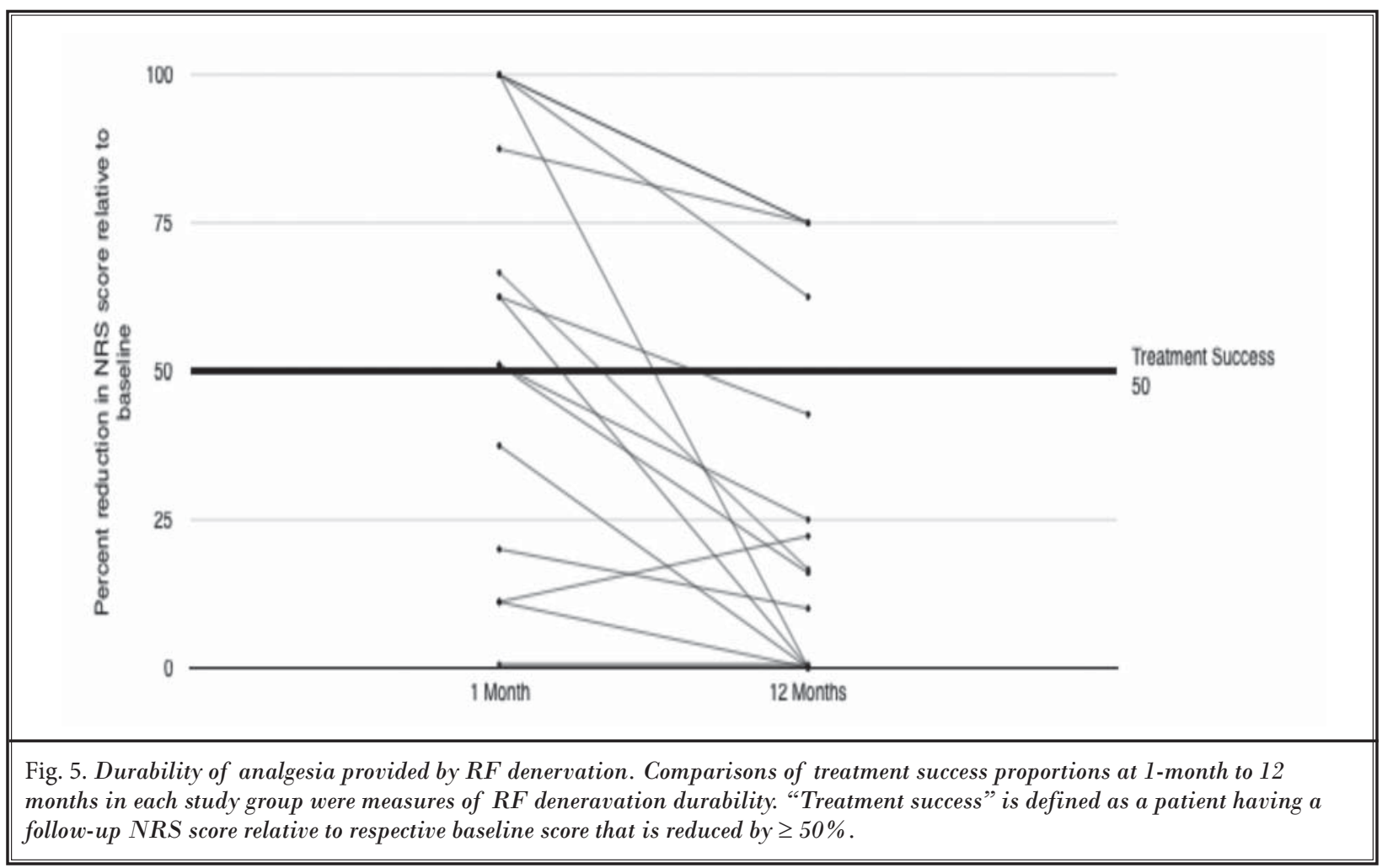

Assessing patients' characteristics associated with positive outcomes was not one of our endpoints; moreover, our population prevents us from reaching definitive conclusions. Safety is a crucial requirement of interventional procedures for pain management, one of the potential risks of HJ PRF is puncturing a major vascular structure such as the femoral vessels. In our case series, we reported only 2 cases of femoral artery puncture during needle placement. In these patients, the procedure was carried out after needle repositioning and, as for all patients, a compressive bandage was applied for 4 hours and patients were discharged only after removal of the bandage and confirmation that no blood was spilling from needle insertion point. Both patients recovered normally and there was no sign of haematoma or other significant complications. Using ultrasound assistance combined with fluoroscopy during needle placement (that we do not use routinely and was never used in our population) could be useful for further risk reduction of the vascular puncture (31).

\section{Limitations}

Small population size, lack of a control group.

\section{Conclusions}

PRF appears to be a safe and effective technique to treat chronic hip pain. Our results suggest that patients could get significant pain relief lasting for at least 6 months. Further investigation is needed to confirm PRF efficacy in a randomized clinical trial comparing PRF to another conservative treatment such as repeated articular injections as well as to placebo. 


\section{References}

1. Fernandes L, Hagen KB, Bijlsma JW, Andreassen $\mathrm{O}$, Christensen $\mathrm{P}$, Conaghan PG, Doherty M, Geenen R, Hammond A, Kjeken I, Lohmander LS, Lund H, Mallen CD, Nava T, Oliver S, Pavelka K, Pitsillidou I, da Silva JA, de la Torre J, Zanoli G, Vliet Vlieland TP. EULAR recommendations for the non-pharmacological core management of hip and knee osteoarthritis. Ann Rheum Dis 2013; 72:1125-1135.

2. Kennedy S, Moran M. Pharmacological treatment of osteoarthritis of the hip and knee. BC Medical Journal 2010; 52:404-409.

3. Birnbaum K, Prescher A, Hessler S. The sensory innervation of the hip joint - an anatomical study. Surg Radiol Anat 1997; 19:371-375.

4. Yavuz F, Yasar E, Ali Taskaynatan M, Goktepe AS, Tan AK. Nerve block of articular branches of the obturator and femoral nerves for the treatment of hip joint pain. J Back Musculoskelet Rehabil 2013; 26:79-83.

5. $\quad$ Flanagan J, Thomas T, Casale F, Desai K. Intra-articular injection for pain relief in patients awaiting hip replacement. Ann $R$ Coll Surg Engl 1988; 70:156-157.

6. Grillet B, Dequeker J. Intra-articular steroid injection. A risk-benefit assessment. Drug Saf 1990; 5:205-211.

7. Brodkey JS, Miyazaki Y, Ervin FR, Mark $\mathrm{VH}$. Reversible heat lesions with radiofrequency current: A method of stereotactic localization. J Neurosurg 1964; 21:49-53.

8. Dieckmann G, Gabriel E, Hassler R. Size, form, and structural peculiarities of experimental brain lesions. Confinia Neurologica 1965; 26:134-142.

9. Smith HP, McWhorter JM, Challa VR. Radiofrequency neurolysis in a clinical model. Neuropathological correlation. J Neurosurg 1981; 55:246-253.

10. Hamann W, Hall S. Acute effect and recovery of primary afferent nerve fibres after graded RF-lesion in anaesthetized rats. Br J Anaesth 1992; 68:443.

11. Frohling MA, Schlote W, Wolburg-Buchholz K. Nonselective nerve fibre damage in peripheral nerves after experimental thermocoagulation. Acta Neurochir (Wien) 1998; 140:1297-1302.

12. Podhajsky RJ, Sekiguchi Y, Kikuchi S, Myers RR. The histologic effects of pulsed and continuous radiofrequency lesions at 42 degrees $C$ to rat dorsal root ganglion and sciatic nerve. Spine 2005; 30:1008-1013.

13. Dreyfuss P, Halbrook B, Pauza K, Joshi A, McLarty J, Bogduk N. Efficacy and validity of radiofrequency neurotomy for chronic lumbar zygapophysial joint pain. Spine 2000; 25:1270-1277.

14. Fukui S, Nosaka S. Successful relief of hip joint pain by percutaneous radiofrequency nerve thermocoagulation in a patient with contraindications for hip arthroplasty. J Anesth 2001; 15:173-175.

15. Fabrizio R, Carlo M, Annaratone G. Percutaneous radiofrequency denervation in patients with contraindications for total hip arthroplasty. Orthopedics 2012; 35:е302-е305.

16. Kawaguchi M, Hashizume K, Iwata $\mathrm{T}$, Furuya $\mathrm{H}$. Percutaneous radiofrequency lesioning of sensory branches of the obturator and femoral nerves for the treatment of hip joint pain. Reg Anesth Pain Med 2001; 26:576-581.

17. Gekht G, Nottmeier EW, Lamer TJ. Painful medial branch neuroma treated with minimally invasive medial branch neurectomy. Pain Med 2010; 11:1179-1182.

18. Van Boxem K, Huntoon M, Van Zundert J, Patijn J, van Kleef $M$, Joosten EA. Pulsed radiofrequency: A review of the basic science as applied to the pathophysiology of radicular pain. Reg Anesth Pain Med 2014; 39:149-159.

19. Sluijter ME, Cosman ER, Rittman WB, van Kleef $M$. The effects of pulsed radiofrequency field applied to the dorsal root ganglion: A preliminary report. Pain Clin 1998; 11:109-117.

20. van Kleef $M$, Spaans $F$, Dingemans $W$, Barendse GA, Floor E, Sluijter ME. Effects and side effects of a percutaneous thermal lesion of the dorsal root ganglion in patients with cervical pain syndrome. Pain 1993; 52:49-53.

21. Chye CL, Liang CL, Lu K, Chen YW, Liliang PC. Pulsed radiofrequency treatment of articular branches of femoral and obturator nerves for chronic hip pain. Clinl Interv Aging 2015; 10:569-574.

22. Wu H, Groner J. Pulsed radiofrequency treatment of articular branches of the obturator and femoral nerves for management of hip joint pain. Pain Pract 2007; 7:341-344

23. Kellgren JH, Lawrence JS. Radiological assessment of osteoarthrosis. Ann
Rheum Dis 1957; 16:494-502.

24. Reijman M, Hazes JM, Pols HA, Bernsen RM, Koes BW, Bierma-Zeinstra SM. Validity and reliability of three definitions of hip osteoarthritis: Cross sectional and longitudinal approach. Ann Rheum Dis 2004; 63:1427-1433.

25. Locher $S$, Burmeister $H$, Böhlen $T$, Eichenberger U, Stoupis C, Moriggi B Siebenrock K, Curatolo M. Radiological anatomy of the obturator nerve and its articular branches: Basis to develop a method of radiofrequency denervation for hip joint pain. Pain Med 2008; 9:291-298

26. Briggs M, Closs JS. A descriptive study of the use of visual analogue scales and verbal rating scales for the assessment of postoperative pain in orthopedic patients. J Pain Symptom Manage 1999; 18:438-446.

27. Farrar JT, Young JP Jr, LaMoreaux L, Werth JL, Poole M. Clinical importance of changes in chronic pain intensity measured on an 11-point numerical pain rating scale. Pain 2001; 94:149-158.

28. Dworkin RH, Turk DC, Wyrwich KW, Beaton D, Cleeland CS, Farrar JT, Haythornthwaite JA, Jensen MP, Kerns RD, Ader DN, Brandenburg N, Burke LB, Cella D, Chandler J, Cowan P, Dimitrova R, Dionne R, Hertz S, Jadad AR, Katz NP, Kehlet H, Kramer LD, Manning DC, McCormick C, McDermott MP, McQuay HJ, Patel S, Porter L, Quessy S, Rappaport BA, Rauschkolb C, Revicki DA, Rothman M, Schmader KE, Stacey BR, Stauffer JW, von Stein T, White RE, Witter J, Zavisic $S$. Interpreting the clinical importance of treatment outcomes in chronic pain clinical trials: IMMPACT recommendations. J Pain 2008; 9:105-121.

29. Dawson J, Fitzpatrick R, Carr A, Murray D. Questionnaire on the perceptions of patients about total hip replacement. ] Bone Joint Surg Br 1996; 78:185-190.

30. Ghahreman A, Ferch R, Bogduk N The efficacy of transforaminal injection of steroids for the treatment of lumbar radicular pain. Pain Med 2010; 11:1149-1168.

31. Chaiban G, Paradis T, Atallah J. Use of ultrasound and fluoroscopy guidance in percutaneous radiofrequency lesioning of the sensory branches of the femoral and obturator nerves. Pain Pract 2014; 14:343-345. 